\section{(6) OPEN ACCESS}

\title{
The economic burden of lung cancer and mesothelioma due to occupational and para- occupational asbestos exposure
}

\author{
Emile Tompa, ${ }^{1,2,3}$ Christina Kalcevich, ${ }^{1}$ Chris McLeod, ${ }^{1,4}$ Martin Lebeau, ${ }^{5}$ \\ Chaojie Song, ${ }^{6}$ Kim McLeod, ${ }^{4}$ Joanne Kim, ${ }^{6}$ Paul A Demers ${ }^{6}$
}

\begin{abstract}
- Additional material is published online only. To view please visit the journal online (http://dx.doi.org/10.1136/ oemed-2016-104173).

'Institute for Work and Health, Toronto, Ontario, Canada ${ }^{2}$ Department of Economics, McMaster University, Hamilton, Ontario, Canada

${ }^{3}$ Dalla Lana School of Public Health, University of Toronto, Toronto, Ontario, Canada ${ }^{4}$ School of Population and Public Health, Faculty of Medicine, University of British Columbia, Vancouver, British Columbia,

Canada

${ }^{5}$ Institut de recherche RobertSauvé en santé et en sécurité du travail (IRSST), Montréal,

Québec, Canada

${ }^{6}$ Occupation Cancer Research Centre, Toronto, Ontario, Canada
\end{abstract}

\section{Correspondence to}

Dr Emile Tompa, Institute for Work \& Health, 481 University Avenue, Suite 800, Toronto, Ontario, Canada M5G 2E9; etompa@iwh.on.ca

Received 28 October 2016 Revised 10 May 2017 Accepted 20 May 2017 Published Online First 29 July 2017

\begin{abstract}
Objectives To estimate the economic burden of lung cancer and mesothelioma due to occupational and paraoccupational asbestos exposure in Canada.

Methods We estimate the lifetime cost of newly diagnosed lung cancer and mesothelioma cases associated with occupational and para-occupational asbestos exposure for calendar year 2011 based on the societal perspective. The key cost components considered are healthcare costs, productivity and output costs, and quality of life costs.
\end{abstract}

Results There were 427 cases of newly diagnosed mesothelioma cases and 1904 lung cancer cases attributable to asbestos exposure in 2011 for a total of 2331 cases. Our estimate of the economic burden is \$C831 million in direct and indirect costs for newly identified cases of mesothelioma and lung cancer and $\$ C 1.5$ billion in quality of life costs based on a value of $\$ C 100000$ per quality-adjusted life year. This amounts to \$C356 429 and \$C652 369 per case, respectively. Conclusions The economic burden of lung cancer and mesothelioma associated with occupational and para-occupational asbestos exposure is substantial. The estimate identified is for 2331 newly diagnosed, occupational and para-occupational exposure cases in 2011, so it is only a portion of the burden of existing cases in that year. Our findings provide important information for policy decision makers for priority setting, in particular the merits of banning the mining of asbestos and use of products containing asbestos in countries where they are still allowed and also the merits of asbestos removal in older buildings with asbestos insulation.

\section{INTRODUCTION}

There is a growing interest in better understanding the extent of occupational cancers and their economic burden to society; yet, few such economic burden studies have been performed. A WHO report ${ }^{1}$ noted that relatively little has been published worldwide on the costing of asbestos-related diseases. It also noted a great variety in methodological approaches used in studies. There are several key challenges to advancing the evidence base on the burden of asbestos-related diseases, namely, the uncertainty of conceptual issues, lack of standardised methodology and limited data availability.

\section{What this paper adds}

- There is a growing interest in better understanding the extent of occupational cancers and their economic burden to society; yet, few such economic burden studies have been performed.

- Though asbestos is an established human carcinogen, there is no published economic burden study on occupational cancer and/ or mesothelioma attributable to asbestos exposure.

- Our estimate of the economic burden of illness in Canada attributable to occupational asbestos exposure is \$C831 million in direct and indirect costs for newly identified cases of mesothelioma and lung cancer in 2011 and $\$ C 1.521$ billion in quality of life costs based on a value of $\$ C 100000$ per quality-adjusted life year. This amounts to \$C356429 and \$C652 369 per case, respectively.

- Our findings provide important information for policy decision makers for priority setting, in particular the merits of banning asbestos in countries where products with asbestos are still used and also the merits of asbestos removal in older buildings with asbestos insulation.

Nonetheless, several studies have been undertaken that consider the economic burden of all or specific occupational injuries and illnesses in various jurisdictions. Leigh has completed some on the economic burden of occupational injuries and illnesses in the USA. ${ }^{2}{ }^{3}$ Similar studies have been undertaken for Australia, ${ }^{4}$ Singapore $^{5}$ and Britain. ${ }^{6}$ In Canada, a more broadly cast series of studies on the economic burden of illness (both work and non-work related) have been undertaken by Health $\mathrm{Canada}^{7}$ and the Public Health Agency of Canada. ${ }^{8}$ A study by Lebeau et al focused exclusively on occupational injuries and illnesses in Quebec. ${ }^{9}$ Several Canadian studies have focused on specific jurisdictions and types of health issues, such as occupational cancers in Alberta ${ }^{10}$ and skin cancer in Canada. ${ }^{11}$ The Centers for Disease Control and Prevention (CDC Foundation) and the American Heart Association regularly publish estimates on the burden of cardiovascular disease 
$\left(\right.$ eg, $\left.{ }^{12,13}\right)$. These are only a sampling of studies we surveyed in the development of the methods for this analysis.

Though asbestos is an established human carcinogen, we were unable to find any peer-reviewed economic burden study on occupational cancer and/or mesothelioma attributable to asbestos exposure. In response to the absence of published studies, the WHO study prepared preliminary tables of components of the burden for several European countries (see Annex 5 in Ref. 1). One study by Driscoll et al identifies worldwide deaths and disability-adjusted life years (DALYs) attributable to lung cancer, leukaemia and malignant mesothelioma caused by workplace exposure including asbestos. ${ }^{14}$ Another study considered only the health service treatment costs for asbestos-related mesothelioma death in Scotland. ${ }^{15}$

The lack of economic burden studies on occupational exposure to asbestos is likely due to data challenges. Specifically, the long latency period from exposure to onset makes it difficult to identify attributable fractions required to estimate cases associated with occupational exposure. In particular, lung cancer attributable to asbestos exposure poses a challenge, since unlike mesothelioma, such cases are clinically indistinguishable from lung cancers attributable to other types of exposures. ${ }^{16}$

Though economic burden studies do not measure the probability of success of options to abate exposure or the opportunity costs of interventions that might be undertaken to reduce the burden, they serve an important information role. ${ }^{17}$ They provide insights into the magnitudes of health and productivity loss and their costs to society. This information can be used to assess how the burden may have changed over time or how a burden from a particular health condition compares to other burdens. It can also help decision makers with priority setting. Burdens that appear particularly onerous may bring attention to the need to (1) increase funding for intervention options known to reduce the burden, (2) evaluate the merits (in terms of health resource implications) of burden reduction efforts from known alternatives that have not yet been evaluated, and (3) invest in research to discover options to reduce the burden in cases where no effective options have yet been identified. With regard to occupationally related asbestos exposure, much effort has been made by advocates to introduce legislation banning the mining of asbestos and importing, manufacturing or using products that contain asbestos. In such cases, information on the societal economic burden of illness associated with asbestos exposure can help inform the merits of such efforts.

Burden estimates are typically reported for a specific calendar year and are sometimes based on costs in that year for all individuals diagnosed with or living with a particular condition. These aggregate costs are also referred to as prevalence costs, because they encompass costs for individuals across the illness trajectory, including new cases and individuals who have been disabled for a long time. Burden studies can also cost incidents longitudinally, starting from onset, and only include new cases. The time period for these longitudinal or incidence cost studies ranges from several months to the individual's lifetime. These two general types of burden studies are not directly comparable, because of differences in the time periods measured and cases included.

In this study, we use the incidence cost approach to estimate the economic burden for Canadian society in the calendar year 2011 of newly diagnosed lung cancer and mesothelioma cases attributable to occupational and para-occupational asbestos exposure. We use the term para-occupational to refer to cases in which the afflicted individual was not exposed through work, but through a family member who brought asbestos fibres into the home from work, sometimes described as 'take-home' exposure. ${ }^{18} \mathrm{We}$ consider mesothelioma and lung cancer together, as they are the two most prevalent cancer-type diseases associated with occupational asbestos exposure.

Our estimates consider lifetime costs incurred by all stakeholders associated with each new case. The key question addressed by this analysis is: What would be the saving to society if we did not have any cases of lung cancer or mesothelioma in 2011 attributable to occupational or para-occupational asbestos exposures? Essentially, the estimated costs reflect the difference between a counterfactual scenario (ie, the road not taken), compared with the current scenario.

\section{METHODOLOGY}

Counts of newly identified lung cancer and mesothelioma cases in 2011 attributable to occupational asbestos exposure were estimated by several members of our research team using an approach similar to the one used by the United Kingdom Burden of Occupational Cancer Study, ${ }^{19}$ but updated for the Canadian context. Asbestos is the only known cause of mesothelioma, and we attributed a proportion of the total number of incident mesothelioma cases in Canada to workplace asbestos exposure based on a review of population-based case-control studies of lung cancer that assessed workplace asbestos exposure. We estimated that $85 \%$ of mesothelioma cases among men and $40 \%$ of mesothelioma cases among women occurred from workplace asbestos exposure. In addition, we estimated that $20 \%$ of female mesothelioma cases were due to para-occupational exposure. We also performed a meta-analysis of the ratio of excess lung cancer cases for every case of mesothelioma observed in cohorts of asbestos-exposed workers using methods similar to those reported by McCormack et al, ${ }^{16}$ but used the ratio derived from North American studies. We applied this ratio to our estimates of attributable mesothelioma cases to arrive at our estimates of occupational asbestos-attributable lung cancers. A fact sheet on these Canadian estimates has been prepared by the Occupational Cancer Research Centre (OCRC) and CAREX Canada. ${ }^{20}$

For our economic burden estimates, we consider three key cost categories-direct costs (primarily healthcare products and services), indirect costs (primarily output and productivity in paid work and in home production) and quality of life costs (social role engagement and the intrinsic value of health). Figure 1 provides a schema for our conceptualisation of health values at the individual level. The schema delineates the value of health at the individual level for labour-market earning purposes and the value of health for social role engagement and the intrinsic value of health. The distinction is important to our methodological approach, since we estimate health impacts on labour-market output and productivity (labelled as indirect costs) separately from health impacts on social role functions (labelled quality of

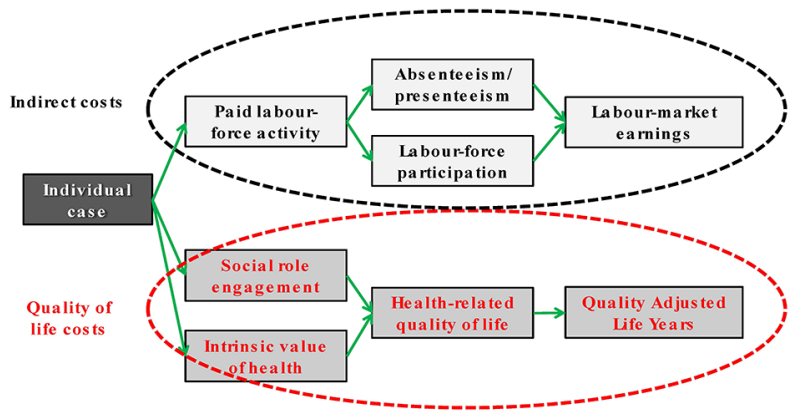

Figure 1 Schema of health valuation at the individual level. 


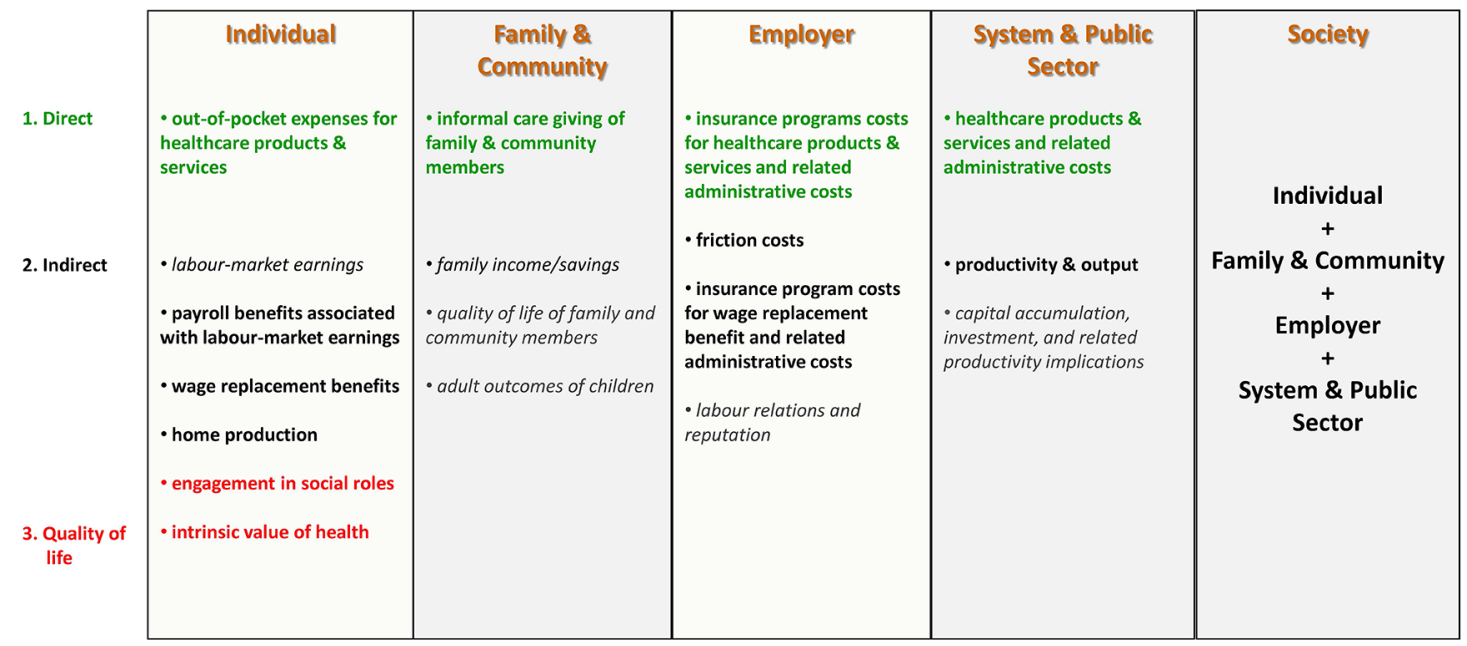

Figure 2 Impacts and related costs by key stakeholder group.

life costs). We also estimate the value of home production separately. The approach has precedence in the economic burden and health-technology assessment literatures, ${ }^{21}$ where health-related quality of life measure are key outcomes considered when assessing the merits of different treatment paradigms. Other recent studies in the occupational health field have also included the health-related quality of life costs as a distinct component (eg, Ref. 9). WHO also emphasises the importance of considering social costs in burden studies, as well as pain and suffering. ${ }^{1}$ This is particularly relevant with older populations, since many are not in the labour force. In such cases, a focus on loss of labourmarket earnings may distort the burden measurement.

We estimated total lifetime costs of newly diagnosed cases in 2011 incurred by all stakeholders (ie, the societal level economic burden), discounting all costs to the 2011 calendar year, using a $3 \%$ discount rate. Figure 2 provides an overview of costs by four key stakeholder groups: (1) individual, (2) family and community, (3) employer and (3) system and public sector. The societal level perspective is simply an aggregation of costs incurred by all stakeholders, with adjustments made to ensure no double counting. Some values drop out of the aggregation, specifically with transfer payments such as wage replacement benefits provided by insurance programs, since in such cases a cost to one stakeholder is simply a benefit to another. The italicised items are cost categories that were not included in our computations, even though they are relevant impacts. They are not quantified due to methodological and data limitations.

We provide a summary of the estimation of the three key components-direct, indirect and quality of life costs. Details are provided in the online supplementary Appendix 1.

\section{Direct costs}

Our starting point for estimating direct costs was the healthcare costs of lung cancer by type and stage identified via the Canadian Cancer Risk Management Model (CRMM). ${ }^{22}$ The model also provided data on survival probabilities. The CRMM only had treatment costs for lung cancer, so we turned to data from a Canadian workers' compensation board to estimate the cost of mesothelioma treatment. Treatment costs are generally higher in the workers' compensation system than the public healthcare system in Canada due to premiums they pay for these services. To account for this, we used the average healthcare costs for lung cancer in the Canadian public healthcare system to estimate the cost for mesothelioma by proportionally adjusting it based on relative costs of mesothelioma versus lung cancer identified in data from the Ontario Workplace Safety and Insurance Board. ${ }^{23}$ For mesothelioma survival, we used data from the US Surveillance, Epidemiology, and End Results (SEER) Registry (http:// seer.cancer.gov/registries/). To these costs, we added healthcare administration in the amount of $16.7 \% .^{24}$ These administration costs are presented separately along with workers' compensation administration costs. A fraction of the occupational cases (but no para-occupational cases) would also be claimed through the Canadian workers' compensation system. We estimated the proportion of cases in that system to be 54\% for mesothelioma and $10 \%$ for lung cancer. ${ }^{25}$ Healthcare and administration costs are higher in workers' compensation, so we used higher rates for those proportions based on data from the Ontario Workplace Safety and Insurance Board. ${ }^{23}$ For these administrative costs, we used 27\% (Association of Workers Compensation Boards of Canada, http://awcbc.org/), which was applied to both direct expenses and transfer payments, even though transfer payments were not included in the final cost estimates.

Other costs estimated for the direct cost component included family and community time in caregiving and out-of-pocket costs for travel to receive care, parking, pharmaceuticals, home healthcare and accommodation. These costs were estimated as an aggregate in two parts, time costs and out-of-pocket costs, rather than estimating each item individually. We assumed 16 hours of caregiving time per week. ${ }^{26}$ Caregiving time was valued at the weighted average provincial minimum wage. To project future minimum wage rates, we increased the average by $2 \%$ per year after calendar year 2015. Out-of-pocket costs were estimated to be $\$$ C548 per month. ${ }^{27}$ Both caregiving and out-of-pocket costs were assumed to increase at $2 \%$ per year over a 10 -year period and were adjusted for survival probabilities for that period.

\section{Indirect costs}

To estimate output and productivity costs, we used both the human capital and friction cost approaches similar to other recent studies. ${ }^{45}$ Societal level output and productivity costs were based on the former. We considered the wage of the individual and the amount of work time lost due to poor health or premature death using survival probabilities from the Canadian CRMM and the SEER Registry, which provided survival probabilities for 10 year following diagnosis. Year-to-year, age-specific 
survival was assumed to be similar to general population after 10 years. Data on labour-force participation following diagnosis was based on Earle et al. ${ }^{28}$ For labour-market earnings, we used the average for working Canadians adjusted for age and sex, which we drew from the Canadian Labour Force Survey from 2011 and the Canadian Survey of Labour and Income Dynamics from 2010 . We assumed a productivity growth rate of $1 \%$ per year. To these values, we added $14 \%$ to account for payroll costs paid by employers, based on employer contribution data from the Canadian National Accounts.

To estimate employer replacement costs of ill workers, we use a variant of the friction cost approach..$^{29}$ This approach is meant to estimate employer's short-term cost of production disturbances associated with employee turnover, which may include costs such as search expenses, management time for interview time, and reduced productivity of the new hire during the training period. We estimated this production disturbance cost as $50 \%$ of 6 months wage of the worker being replaced. These costs were assumed to be incurred in the year of diagnosis.

Home production costs were estimated only for mortality, not morbidity (ie, home production values foregone only after death). The exclusion of home production costs for morbidity cases invariably results in an underestimate of these costs (Leigh, p746). ${ }^{2}$ Drawing on data from Statistics Canada's General Social Survey from 2005, we identified average daily hours of home production by sex and 10-year age bracket for individuals identifying time spent in home production and multiplied this by 365 to estimate yearly hours. For sensitivity analysis, we considered the average daily hours of home production by sex and 10-year age bracket for all individuals (see online supplementary Appendix 1 for details). To estimate monetary values, we used the wage rate for housekeepers and related occupations (occupation code 4412) from the Survey of Employment, Payrolls and Hours (SEPH). No payroll costs were added to this rate, and productivity was assumed to be constant over time.

\section{Quality of life costs}

Health-related quality of life costs were captured with quality-adjusted life years (QALYs). This is a preference-based measure that combines the morbidity in a particular health state and time in that state by means of a weight that is between zero (death) and one (a year in perfect health). Conceptually, QALYs are constructed such that they do not include consideration of earnings from labour-market activity or other sources; hence, this fact allows us to capture output and productivity impacts separately as we have described above. Since there is some controversy about overlap, we present these estimates separately, as well as including them in the total burden.

QALY weights and conditional life expectancies for cases were drawn from the Canadian CRMM, the SEER Registry and Arnold et al. ${ }^{30}$ Health-related quality of life and year-to-year age-specific survival is assumed to be similar to general population after 10 years. Case QALYs were compared with population average QALYs (drawn from the 2010 Canadian Community Health Survey), adjusted for age, sex and population life expectancy, the latter based on the 2009-2011 Canada Life Tables (details provided in the online supplementary Appendix 1) QALYs for 2012 onwards were discounted to 2011 calendar year using a $3 \%$ discount rate.

The health policy and contingent-valuation literatures offer a range of monetary values for a QALY. ${ }^{21}{ }^{31-34}$ We used \$C 100000 , which is in the mid-range of the values identified in these literatures. We also undertook sensitivity here, given that it was the largest of the three key components, by using \$C 50000 and \$C 25000 for a QALY. The former value was commonly used in the Canadian health technology assessment field in the 1990s. It is still a reference threshold, but because it is static in time (not updated since 1992), it is now more of a lower bound threshold. Neumann et al note that there is no accepted standard for what constitutes a good value, although the range from \$C50 000 to \$C100 000 per QALY has often been used as a rough benchmark in the USA. ${ }^{35}$

\section{RESULTS}

There were 427 cases of newly diagnosed mesothelioma cases and 1904 lung cancer cases attributable to asbestos exposure in 2011, for a total of 2331 cases. Fifty-seven of the mesothelioma cases were women, 38 of which were occupational and 19 para-occupational. Of the 2331 cases, $90 \%$ were men and $10 \%$ women. In terms of the age distribution of these cases, most (90\%) were 60 years or older. Consequently, lost labourmarket output and productivity was not a large component of the total burden, as might be expected if the cohort was younger. Since many countries are extending age of retirement to late $60 \mathrm{~s}$ and even 70, future burden studies may take this phenomenon into consideration. In our case, we have used historical labourmarket engagement/earnings and retirement patterns, so it is not factored into our results.

Both mesothelioma and lung cancer have poor survival prognosis, though survival probabilities are higher for lung cancer. Survival through the first year is $42.4 \%$ for mesothelioma and $46.4 \%$ for lung cancer. For 10 years, it is $4.2 \%$ and $9.1 \%$. As a result, healthcare costs are low for mesothelioma, since many individuals die shortly after diagnosis and treatment is often focused on palliative care. Though survival probabilities factor into direct, indirect and quality of life costs for cases, the biggest impact is on loss of quality of life and its related monetary value.

Tables 1 and 2 provide breakdowns of the economic burden. For mesothelioma, the total societal burden is \$C482 million or \$C1 130398 per case, with direct and indirect costs comprising $39 \%$ and quality of life costs $61 \%$. For lung cancer, the total societal burden is \$C1 869 million or \$C981576 per case, with direct and indirect costs comprising $34 \%$ and quality of life costs $66 \%$. The total combined burden sums to \$C2 352 million. These estimates are based on the value of \$C100 000 for a QALY.

Sensitivity analysis was undertaken with values of \$C50000 and \$C25000 for a QALY. With the \$C50000 value, the total burden of mesothelioma is \$C334 million and for lung cancer \$C1 257 million, for a total of \$C1 591 million. With the \$C25000 value, the total burden of mesothelioma is \$C260 million and for lung cancer \$C951 million, for a total of \$C1 211 million. Given that the quality of life component is the largest part of the burden, the value placed on a QALY has important impact on the total burden. In this case, using a more conservative estimate, the total burden dropped to $67.6 \%$ of the original estimate with the $\$ \mathrm{C} 50000$ value and to $51.5 \%$ with the \$C25 000 value.

An alternative way to avoid double counting is to subtract values that may be double counted, in this case the productivity and output costs. If we exclude these, the total burden of mesothelioma is \$C365 million and for lung cancer \$C1371 million, for a total of \$C1736 million.

We also undertook sensitivity analysis for home production, using more modest values of daily hours of time use, since average home production hours are somewhat higher than a 


\begin{tabular}{|c|c|c|c|c|}
\hline $\begin{array}{l}\text { Based on } 427 \text { cases } \\
\text { in } 2011\end{array}$ & All cases & & Per case & \\
\hline Total healthcare costs & \$C23 212416 & & $\$ C 54393$ & \\
\hline $\begin{array}{l}\text { Healthcare sector } \\
\text { treatment costs }\end{array}$ & & \$C17 130994 & & $\$ C 40143$ \\
\hline $\begin{array}{l}\text { Out-of-pocket } \\
\text { costs }\end{array}$ & & $\$ C 6081422$ & & $\$ C 14251$ \\
\hline $\begin{array}{l}\text { Total productivity and } \\
\text { output costs }\end{array}$ & \$C117 844178 & & $\$ C 276143$ & \\
\hline $\begin{array}{l}\text { Wage and salary } \\
\text { costs }\end{array}$ & & \$C26 501873 & & $\$ C 62102$ \\
\hline $\begin{array}{l}\text { Fringe benefit } \\
\text { costs }\end{array}$ & & \$C3 710262 & & $\$ C 8694$ \\
\hline $\begin{array}{l}\text { Home production } \\
\text { costs }\end{array}$ & & \$C87 632043 & & $\$ C 205347$ \\
\hline Total friction costs & \$C2 360170 & & \$C5 531 & \\
\hline $\begin{array}{l}\text { Total informal care } \\
\text { giving costs }\end{array}$ & $\$ C 5790544$ & & $\$ C 13569$ & \\
\hline $\begin{array}{l}\text { Total insurance } \\
\text { administration costs }\end{array}$ & \$C36 886993 & & $\$ C 86437$ & \\
\hline $\begin{array}{l}\text { Healthcare } \\
\text { administration } \\
\text { costs }\end{array}$ & & \$C2 574720 & & $\$ C 6033$ \\
\hline $\begin{array}{l}\text { Workers' } \\
\text { compensation } \\
\text { administration } \\
\text { costs }\end{array}$ & & \$C34 312273 & & $\$ C 80404$ \\
\hline $\begin{array}{l}\text { Total health-related } \\
\text { quality of life costs }\end{array}$ & $\$ C 296,303,160$ & & $\$ C 694325$ & \\
\hline Overall total costs & \$C482 397461 & & \$C1 130398 & \\
\hline
\end{tabular}

*2011 Canadian dollars.

US study by Grosse $e t$ al. ${ }^{36}$ Revised burden estimates for home production are 13\% lower \$C179605 per case for mesothelioma and \$C163 061 for lung cancer.

\section{DISCUSSION}

Our estimate of the economic burden of illness in Canada attributable to occupational asbestos exposure is \$C831 million in direct and indirect costs for newly identified cases of mesothelioma and lung cancer in 2011 and \$C1.521 billion in quality of life costs based on a value of $\$ C 100000$ per QALY. This amounts to \$C356429 and \$C652369 per case, respectively. Our estimate of the economic burden of illness is \$C2.352 billion for newly identified cases of mesothelioma and lung cancer in 2011. To put it into perspective, the Canadian economy had a gross domestic product of $\$ \mathrm{C} 1.8$ trillion that year, so the burden identified represents $0.131 \%$ of this amount. Though this fraction may not seem large, the monetary amount is nonetheless substantive, particularly given that it is only newly diagnosed cases and a conservative estimate of the incidence of illness and related costs due to asbestos exposure. We did not consider other illnesses known to be attributable to asbestos exposure such as pleural plaque and several other cancers, nor have we included non-occupational exposure cases.

Our estimates are of value to current efforts to reduce occupational and non-occupational asbestos exposure in Canada and may also be of value to other countries in this regard. Though the last asbestos mines in Canada were closed in 2011, exposure through the import and use of products containing asbestos continues, particularly in the construction industry. There is no ban on the import and use of such products, though there are
Table 2 Economic burden of asbestos-related lung cancer*

\begin{tabular}{|c|c|c|c|c|}
\hline $\begin{array}{l}\text { Based on } 1904 \\
\text { cases in } 2011\end{array}$ & All cases & & Per case & \\
\hline $\begin{array}{l}\text { Total healthcare } \\
\text { costs }\end{array}$ & \$C81 831543 & & \$C42 974 & \\
\hline $\begin{array}{l}\text { Healthcare sector } \\
\text { treatment costs }\end{array}$ & & \$C46 154063 & & $\$ C 24238$ \\
\hline $\begin{array}{l}\text { Out-of-pocket } \\
\text { costs }\end{array}$ & & $\$ C 35677480$ & & $\$ C 18736$ \\
\hline $\begin{array}{l}\text { Total productivity } \\
\text { and output costs }\end{array}$ & \$C498 309077 & & \$C261690 & \\
\hline $\begin{array}{l}\text { Wage and salary } \\
\text { costs }\end{array}$ & & \$C126 275066 & & $\$ C 66314$ \\
\hline $\begin{array}{l}\text { Fringe benefit } \\
\text { costs }\end{array}$ & & \$C15 507464 & & \$C8 144 \\
\hline $\begin{array}{l}\text { Home production } \\
\text { costs }\end{array}$ & & \$C356 526546 & & $\$ C 187232$ \\
\hline Total friction costs & \$C10 542816 & & \$C5 537 & \\
\hline $\begin{array}{l}\text { Total informal care } \\
\text { giving costs }\end{array}$ & \$C32 857086 & & $\$ C 17255$ & \\
\hline $\begin{array}{l}\text { Total insurance } \\
\text { administration costs }\end{array}$ & \$C21 201183 & & \$C11 134 & \\
\hline $\begin{array}{l}\text { Healthcare } \\
\text { administration } \\
\text { costs }\end{array}$ & & \$C7 627244 & & $\$ C 4005$ \\
\hline $\begin{array}{l}\text { Workers' } \\
\text { compensation } \\
\text { administration } \\
\text { costs }\end{array}$ & & \$C13 573939 & & $\$ C 7128$ \\
\hline $\begin{array}{l}\text { Total health-related } \\
\text { quality of life costs }\end{array}$ & \$C1 224370103 & & \$C642986 & \\
\hline Overall total costs & \$C1 869111809 & & \$C981576 & \\
\hline
\end{tabular}

some regulations on their use. Additionally, there is an accumulation of asbestos in the built environment such as schools, hospitals and homes from more than a century of its use in construction. There is currently no systematic approach taken at the national level to document the level of exposure in the Canadian population. The WHO report (2013) also notes that asbestos continues to present a public health risk in Europe and that the recognition, diagnosis and recording of asbestos-related diseases remain a challenge in many countries. ${ }^{1}$

Administrative records for workers' compensation boards across Canada indicate that work-related fatalities from mesothelioma are on the rise and may continued to grow in the near future (Associate of Workers' Compensation Boards of Canada, www.awcbc.ca), so the economic burden is likely to increase as well. Between 2007 and 2012, there were 1207 fatalities. In fact, mesothelioma was the most common cause of work-related fatalities during this time period. We note also that in our estimates, we did not include transfer payment to claimants and their families; yet, this is a cost incurred by employers and factors into their cost of doing business. The average cost of a workers' compensation claim for mesothelioma provides some insights into the magnitude of such costs-in Ontario it is \$C532844. This estimate does not include litigation costs incurred by the insurance providers, employers and other stakeholders.

Our study is the first academic study we are aware of that has estimated the societal-level economic burden of illness associated with occupational and para-occupational asbestos exposure. We have been inclusive of costs borne by different stakeholders and have considered three broad categories of costs-direct, indirect and quality of life costs. Our effort can serve academics 
and policy makers seeking to inform policy decision-making processes in other countries, as it provides a methodological platform for them to quantify the economic burden of asbestos exposure in their jurisdictions.

In our review of the literature, we noted that there are different cost considerations used to estimate burdens, and this is likely due to a lack of standardisation in the form of a reference case (ie, a set of methodological criteria, based on professional scientific consensus, to serve as a best practice guidelines and referred to when undertaking such analyses). There is a convention in published burden estimates to include the sum of medical and productivity costs. In fact, most studies contain these components and many contain only these. But how these components are estimated and their underlying assumptions can vary dramatically. For example, some use the human capital approach to estimate productivity impacts, others the friction cost approach, and yet others willingness-to-pay or statistical value of human life approaches. ${ }^{1}$ Furthermore, there is lack of consensus on if and how to include the social cost of illness and health-related quality of life measures. But as noted in the WHO report 'loss of earnings does not accurately reflect the social cost of illness' (WHO, p54). ${ }^{1}$ The primary benefit of standardisation is that it ensures studies are based on sound economic principles and makes the results of different studies more readily comparable. This, in turn, can facilitate the uptake of evidence by policymakers. Ideally, a reference case allows for deviation from prescriptions when necessary, as for example due to data limitations, as long as justification is provided for such deviations.

We note that the valuation of health in social role functions is a particular area of measurement that varies across economic burden and evaluation studies. Some studies use QALYs (or another health-related quality of life measure), particularly in the health technology field, others use contingent valuation methods (eg, environmental field), and yet others use the statistical value of health and life (eg, transportation industry). The conversion of non-monetary health measure to monetary estimates is also an issue. For our estimates, we used a mid-range value of \$C100 000 for a QALY and also undertook sensitivity analysis, using lower values to identify more conservative estimates.

Going forward, researchers working in the health and safety policy arena might consider focusing on both further developing economic burden and economic evaluation methods in this field (including the development of a reference case or gold standard) and promoting their application for the evaluation of burdens and intervention alternatives to abate them. Our study and the related appendix (see online supplementary Appendix 1) provide an example of how the conceptual underpinnings of economic burden measurement can be applied in relatively unchartered terrain with data from a number of published and unpublished sources. Undoubtedly, some assumptions (and sometimes compromises) needed to be made to address data gaps. In our study, we have attempted to document them as thoroughly as possible. Thus, our efforts can give insight to administrators, data collectors and academics of where further fieldwork might be undertaken.

\section{SUMMARY AND CONCLUSIONS}

The total cost to Canadian society of newly diagnosed cases in 2011 of mesothelioma and lung cancer from occupational-related asbestos exposure is \$C831 million for direct and indirect costs and \$C1.521 billion for quality of life costs. The latter is based on a value of \$C100 000 per QALY. The per-case average lifetime cost is \$C356429 and \$C652 369, respectively. The breakdown of this cost into key components is as follows: $35 \%$ of the cost is attributable to direct and indirect costs and $65 \%$ to losses in health-related quality of life. This burden estimate is large; yet, it is only the tip of the total economic burden, since it includes only 2331 newly diagnosed occupational and para-occupational cases from one calendar year. The number of new cases is predicted to grow in the near future, even though asbestos is no longer mined in Canada, due to the long latency of onset and the continuation of occupational exposures experienced by workers, particularly in the construction industry. We have not included in our estimates other occupational diseases that are associated with asbestos exposure, such as pleural plaque and several other cancers, and non-occupational exposure, so our estimate of the societal economic burden of new cases in Canada is likely a conservative one. Our methods provide a template for estimates of asbestos-related disease burden in other countries.

Contributors ET: Principal investigator/guarantor of the study. Led the conceptual and methodological design of the economic component of the study, provided analytic oversight and was the lead pen of the manuscript. CK: Study co-investigator. Contributed to the conceptual and methodological design of the economic component of the study, prepared a first cut of the computations, assisted in preparing the methods write-up, reviewed drafts of the manuscript and provided editorial suggestions. CML: Study co-investigator. Contributed to the conceptual and methodological design of the economic and epidemiological components of the study, reviewed drafts of the manuscript and provided editorial suggestions. ML: Study co-investigator. Contributed to the conceptual and methodological design of the economic component of the study, reviewed drafts of the manuscript and provided editorial suggestions. CS and JK: Study co-investigator. Contributed to the conceptual and methodological design of the epidemiological component of the study, reviewed drafts of the manuscript and provided editorial suggestions. KML: Study co-investigator. Contributed to the evidence synthesis of the literature on occupational asbestos exposure, reviewed drafts of the manuscript and provided editorial suggestions. PAD: Project team lead. Led the conceptual and methodological design of the epidemiological component of the study, reviewed drafts of the manuscript and provided editorial suggestions. All authors have participated in the conception and writing of this manuscript and have read the final version of the manuscript. The manuscript represents honest work.

Funding This study was funded by the Canadian Cancer Society (grant number 701285-00). The funding was provided as competitive peer-reviewed research funding. The sponsors had no access to study data or involvement in the drafting of and decision to publish the article.

Competing interests None declared.

Patient consent Detail has been removed from this case description/these case descriptions to ensure anonymity. The editors and reviewers have seen the detailed information available and are satisfied that the information backs up the case the authors are making.

Provenance and peer review Not commissioned; externally peer reviewed.

Open Access This is an Open Access article distributed in accordance with the Creative Commons Attribution Non Commercial (CC BY-NC 4.0) license, which permits others to distribute, remix, adapt, build upon this work non-commercially, and license their derivative works on different terms, provided the original work is properly cited and the use is non-commercial. See: http://creativecommons.org/ licenses/by-nc/4.0/

(c) Article author(s) (or their employer(s) unless otherwise stated in the text of the article) 2017. All rights reserved. No commercial use is permitted unless otherwise expressly granted.

\section{REFERENCES}

1 World Health Organization. The human and financial burden of asbestos in the WHO European region: meeting report, Bon, Germany. Copenhagen: WHO Regional Office for Europe, 2013. http://www.euro.who.int/_data/assets/pdf_file/0003/194133/RBAsbestos-Mtg-Report-Bonn-2012.pdf (accessed 17 Feb 2017).

2 Leigh JP. Economic burden of occupational injury and illness in the United States. Milbank Q 2011;89:728-72

3 Leigh JP, Waehrer G, Miller TR, et al. Costs of occupational injury and illness across industries. Scand J Work Environ Health 2004;30:199-205. 
4 Safe Work Australia. The cost of work-related injury and illness for Australian employers, workers and the community: 2008-09. Canberra: Safe Work Australia, 2012.

5 Loke YY, Tan WJ, Manickam K, et al. Economic cost of work-related injuries and illhealth in Singapore. Singapore: WSH Institute, 2013.

6 Health and Safety Executive. The costs to Britain of workplace injuries and workrelated ill health in 2006/07: workplace fatalities and self reports. Warrington: Risk Solutions, 2011.

7 Health Canada. Economic burden of Illnessillness in Canada, 1998. Ottawa: Health Canada, 2002

8 Public Health Agency of Canada. Economic burden of illness in Canada, 2005-2008. Ottawa: Public Health Agency of Canada, 2014.

9 Lebeau M, Duguay P, Boucher A. Costs of occupational injuries and diseases in Québec. J Safety Res 2014;50:89-98.

10 Orenstein MR, Dall T, Curley P, et al. The economic burden of occupational cancers in Alberta. Calgary: Alberta Health Services, 2010.

11 Krueger $\mathrm{H}$, Williams D, Chomiak M, et al. The economic burden of skin cancer in Canada: current and projected. Final report. Canadian partnership against cancer, 2010.

12 CDC Foundation. Heart disease and stroke cost America nearly \$1 billion a day in medical costs, lost productivity. CDC Foundation, 2015. http://www.cdcfoundation. org/pr/2015/heart-disease-and-stroke-cost-america-nearly-1-billion-day-medicalcosts-lost-productivity (accessed 17 Feb 2017).

13 American Heart Association. Heart disease and stroke statistics-2015 update: a report from the American Heart Association. AHA 2015 http://circ.ahajournals.org/ content/early/2014/12/18/CIR.0000000000000152 (accessed 17 Feb 2017).

14 Driscoll T, Nelson DI, Steenland K, et al. The global burden of disease due to occupational carcinogens. Am J Ind Med 2005;48:419-31.

15 Watterson A, Gorman T, Malcolm C, et al. The economic costs of health service treatments for asbestos-related mesothelioma deaths. Ann N Y Acad Sci 2006; 1076:871-81

16 McCormack V, Peto J, Byrnes G, et al. Estimating the asbestos-related lung Cancer burden from mesothelioma mortality. Br J Cancer 2012;106:575-84.

17 Tompa E, Lund J, Yabroff R. Chapter 15: Health economics and cancer survivorship. In: Feuerstein E, Ganz P, eds. Health services for cancer survivors Springer, 2011.

18 Donovan EP, Donovan BL, McKinley MA, et al. Evaluation of take home (paraoccupational) exposure to asbestos and disease: a review of the literature. Crit Rev Toxicol 2012;42:703-31

19 Brown T, Darnton A, Fortunato L, et al. Occupational cancer in Britain. Respiratory cancer sites: larynx, lung and mesothelioma. Br J Cancer 2012;107(Suppl 1):S56-70.

20 OCRC and CAREX. Asbestos: burden of occupational cancer facts sheet. http://web. uvic.ca/ ssrl01/CAREXtemp/CAREX\%200CRC\%20Burden\%20of\%200ccupational\% 20Cancer $\% 20-\% 20$ Asbestos\%20fact \%20sheet\%20(Dec-16).pdf (accessed 17 Feb 2017).
21 Mackenbach J, Meerding WJ, Kunst A. Economic implications of socioeconomic inequalities in health in the European Union. J Epidemio/ Community Health 2011;65:412-9.

22 Evans WK, Wolfson MC, Flanagan WM, et al. Canadian cancer risk management Model: evaluation of cancer control. Int J Technol Assess Health Care 2013;29:131-9.

23 Workplace Safety and Insurance Board. Follow-up questions and information requests to funding review. $2011 \mathrm{https}: / /$ www.google.ca/ url sa $=t \& r c t=j \& q=\& e s r c=s \&$ source $=$ web \& $c d=1 \& v e d=0$ ahUKEwibmeWy36fKAh WEPB4KHTRYDVIQFggcMAA\&url=http $\% 3$ A \%2F\%2Fwww.wsib.on.ca\%2Fcs \%2Fidcp Ig\%3FIdcService\%3DGET_FILE\%26dDocName\%3DWSIB012535\%26RevisionSelect onMethod\%3DLatestReleased\&usg=AFQjCNGCxpAX5IzH3rVTi0Gvq4oT7kT7eg\& cad=ria (accessed 13 Jan 2016).

24 Woolhandler S, Campbell T, Himmelstein DU. Costs of health care administration in the United States and Canada. N Engl J Med 2003;349:768-75.

25 Del Bianco A, Demers PA. Trends in compensation for deaths from occupational cancer in Canada: a descriptive study. CMAJ Open 2013;1:E1-6.

26 Van Houtven CH, Ramsey SD, Hornbrook MC, et al. Economic burden for informal caregivers of lung and colorectal Cancer patients. Oncologist 2010;15:883-93.

27 Longo CJ, Fitch M, Deber RB, et al. Financial and family burden associated with cancer treatment in Ontario, Canada. Support Care Cancer 2006;14:1077-85.

28 Earle CC, Chretien Y, Morris C, et al. Employment among survivors of lung cancer and colorectal cancer. J Clin Oncol 2010;28:1700-5.

29 Koopmanschap MA, Rutten FF, van Ineveld BM, et al. The friction cost method for measuring indirect costs of disease. J Health Econ 1995;14:171-89.

30 Arnold DT, Hooper CE, Morley A, et al. The effect of chemotherapy on healthrelated quality of life in mesothelioma: results from the SWAMP trial. Br J Cancer 2015;112:1183-9.

31 Appleby J, Devlin N, Parkin D. NICE's cost effectiveness threshold. BMJ 2007:335:358-9.

32 QALYs: the Canadian experience. Applied pharmacoeconomics and research Forum at the University of California, San Diego. 2007 http://pharmacy.ucsd.edu/faculty/ AppliedPEForum/docs/QALYs_The_Canadian_Experience_may_25_posting.pdf (accessed 13 Jan 2016)

33 Hirth RA, Chernew ME, Miller E, et al. Willingness to pay for a quality-adjusted life year. Medical Decision Making 2000;20:332-42.

34 Khor S, Djalalova D, Hoch JThe paradox of the Laupacis Parallax. Presentation at the CADH 2010 symposium, evidence advice, recommendations delivery of value for money in health care for Canadians, Halifax, Nova Scotia, Canada. 2010.

35 Neumann PJ, Sandberg EA, Bell CM, et al. Are pharmaceuticals cost-effective? A review of the evidence. Health Aff 2000;19:92-109.

36 Grosse SD, Krueger KV, Mvundura M. Economic productivity by age and sex: 2007 estimates for the United States. Med Care 2009:47:S94-103. 